\title{
Contrasting the Role of xCT and GLT-1 Upregulation in the Ability of Ceftriaxone to Attenuate the Cue-Induced Reinstatement of Cocaine Seeking and Normalize AMPA Receptor Subunit Expression
}

\author{
Amber L. LaCrosse, ${ }^{1}$ Sinead M. 0’Donovan, ${ }^{3}{ }^{\circledR}$ Marian T. Sepulveda-Orengo, ${ }^{2}$ Robert E. McCullumsmith, ${ }^{3}$ \\ Kathryn J. Reissner, ${ }^{2}$ Marek Schwendt, ${ }^{1}$ and Lori A. Knackstedt ${ }^{1}$ \\ ${ }^{1}$ Psychology Department, University of Florida, Gainesville, Florida 32611, ${ }^{2}$ Department of Psychology and Neuroscience, University of North Carolina, \\ Chapel Hill, North Carolina 27599, and ${ }^{3}$ Department of Psychiatry and Behavioral Neuroscience, University of Cincinnati, Cincinnati, Ohio 45267
}

Long-term treatment with ceftriaxone attenuates the reinstatement of cocaine seeking while increasing the function of the glutamate transporter 1 (GLT-1) and system xC- (Sxc) in the nucleus accumbens core (NAc). Sxc contributes the majority of nonsynaptic extracellular glutamate in the NAc, while GLT-1 is responsible for the majority of glutamate uptake. Here we used antisense to decrease the expression of GLT-1 and xCT (a catalytic subunit of $\mathrm{Sxc}$ ) to determine the relative importance of both proteins in mediating the ability of ceftriaxone to prevent cue-induced reinstatement of cocaine seeking and normalize glutamatergic proteins in the NAc of rats. Intra-NAc XCT knockdown prevented ceftriaxone from attenuating reinstatement and from upregulating GLT-1 and resulted in increased surface expression of AMPA receptor subunits GluA1 and GluA2. Intra-NAc GLT-1 knockdown also prevented ceftriaxone from attenuating reinstatement and from upregulating xCT expression, without affecting GluA1 and GluA2 expression. In the absence of cocaine or ceftriaxone treatment, xCT knockdown in the NAc increased the expression of both GluA1 and GluA2 without affecting GLT-1 expression while GLT-1 knockdown had no effect. PCR and immunoprecipitation of GLT-1 revealed that ceftriaxone does not upregulate GLT-1 and xCT through a transcriptional mechanism, and their coregulation by ceftriaxone is not mediated by physical interaction. These data support important and distinct roles for xCT and GLT- 1 in the actions of ceftriaxone and add to a body of literature finding evidence for coregulation of these transporters. Our results also point to xCT expression and subsequent basal glutamate levels as being a key mediator of AMPA receptor expression in the NAc.

Key words: glutamate; glutamate transporters; microdialysis; nucleus accumbens; relapse

\section{Significance Statement}

Ceftriaxone attenuates the reinstatement of cocaine, alcohol, and heroin seeking. The mechanism of action of this behavioral effect has been attributed to glutamate transporter 1 (GLT-1) and xCT (a catalytic subunit of Sxc)/Sxc upregulation in the nucleus accumbens core. Here we used an antisense strategy to knock down GLT-1 or xCT in the nucleus accumbens core and examined the behavioral and molecular consequences. While upregulation of both xCT and GLT-1 are essential to the ability of ceftriaxone to attenuate cue-induced reinstatement of cocaine seeking, each protein uniquely affects the expression of other glutamate receptor and transporter proteins. We also report that reducing basal glutamate levels through the manipulation of XCT expression increases the surface expression of AMPA receptor subunits, providing insight to the mechanism by which cocaine alters AMPA surface expression.

\section{Introduction}

Cocaine (Coc) addiction is a chronic disease that is characterized by an inability to regulate drug seeking, resulting in a high rate of

Received Dec. 2, 2016; revised April 28, 2017; accepted May 1, 2017.

Author contributions: R.E.M., M.S., and L.A.K. designed research; A.L.L., S.M.O., M.T.S.-0., K.J.R., and M.S. performed research; A.L.L., M.T.S.-O., K.J.R., and L.A.K. analyzed data; A.L.L., S.M.O., R.E.M., K.J.R., M.S., and L.A.K. wrote the paper.

This work was funded by National Institutes of Health Grants DA-033436 and DA-037270 awarded to L.A.K.; DA-041455 awarded to K.J.R.; and MH-94445, MH-107457, and MH-107916 awarded to R.E.M. We thank Lizhen Wu for her excellent technical assistance on this project. relapse (O'Brien, 2003). Relapse is modeled in animals with the self-administration and reinstatement paradigm, where a drugreinforced response is extinguished and reinstated with one of the stimuli that causes relapse in humans (e.g., a drug-associated cue; Epstein et al., 2006). Glutamate efflux in the nucleus accumbens

The authors declare no competing financial interests.

Correspondence should be addressed to Dr. Lori A. Knackstedt, Psychology Department, University of Florida, 945 Center Drive, Gainesville, FL 32611. E-mail: knack@ufl.edu.

DOI:10.1523/JNEUROSCI.3717-16.2017

Copyright $\odot 2017$ the authors $\quad 0270-6474 / 17 / 375809-13 \$ 15.00 / 0$ 
core (NAc) accompanies the reinstatement of cocaine seeking prompted by cues, cocaine, and context (McFarland et al., 2003; LaCrosse et al., 2016; Smith et al., 2017). Accordingly, the antagonism of NAc AMPA (Cornish and Kalivas, 2000; Xie et al., 2012) and mGlu5 receptors (Wang et al., 2013) attenuates the reinstatement of cocaine seeking.

Several NAc adaptations occur 2-3 weeks after cocaine administration that facilitate an increase in glutamate efflux during reinstatement (for review, see Mulholland et al., 2016). System $\mathrm{xc}-(\mathrm{Sxc})$ contributes the majority of extracellular basal glutamate in the Nac, and its function is decreased following cocaine administration (Baker et al., 2002, 2003), likely leading to a loss of tone on mGlu2/3 autoreceptors (Moussawi et al., 2011). Glutamate reuptake is also disrupted by cocaine. The glial glutamate transporter 1 (GLT-1) is responsible for $90 \%$ of all CNS uptake (Haugeto et al., 1996; Tanaka et al., 1997), and its expression and function are decreased in the NAc of cocaine-extinguished animals (Knackstedt et al., 2010a).

Postsynaptic adaptations are also observed in the NAc 2-3 weeks following cocaine administration. Cocaine self-administration and extinction training results in an inability to induce LTP by stimulating PFC afferents to the NAc, indicating that these neurons are already in an LTP-like state (Moussawi et al., 2009). We previously observed a potentiation of both spontaneous EPSCs (sEPSCs) and evoked EPSCs in the NAc of rats that were extinguished from cocaine self-administration (Trantham-Davidson et al., 2012).

Chronic treatment with the antibiotic ceftriaxone (Cef) increases NAc expression of GLT-1 and xCT (the catalytic subunit of $\mathrm{Sxc}$ ) and attenuates the reinstatement of cocaine seeking (Sari et al., 2009; Knackstedt et al., 2010a). We have shown that Cef increases basal extracellular glutamate in the NAc via increased Sxc activity and also prevents glutamate efflux during reinstatement of cocaine seeking (Trantham-Davidson et al., 2012). Cef also normalizes potentiated evoked EPSC and sEPSC amplitude observed following cocaine (Trantham-Davidson et al., 2012). We previously determined that following abstinence from cocaine (without extinction), the expression of the AMPA subunit GluA1 is increased and Cef normalizes this expression (LaCrosse et al., 2016).

The present work is aimed at understanding the relative importance of $\mathrm{xCT}$ and GLT-1 upregulation in mediating the ability of ceftriaxone to attenuate cue-primed reinstatement of cocaine seeking and normalize the NAc glutamatergic synapse. Acute intra-NAc treatment with a GLT-1 antagonist prevents Cef from attenuating cue-primed reinstatement (Fischer et al., 2013). Because Cef is administered chronically and exerts long-lasting changes in glutamate homeostasis (Sondheimer and Knackstedt, 2011), we used an antisense (AS) strategy to prevent GLT-1 or $\mathrm{xCT}$ upregulation for the duration of Cef treatment to understand how preventing such upregulation by Cef dysregulates the NAc synapse.

We tested the hypothesis that the restoration of basal extracellular glutamate by Cef underlies its ability to normalize synaptic strength through modifying AMPA receptor expression. GluA1 is increased in NAc synaptosomes (Ghasemzadeh et al., 2009) but not in the postsynaptic density (Knackstedt et al., 2010b) following extinction from cocaine self-administration. Further, NAc GluA2 total expression is increased following $30 \mathrm{~d}$ of abstinence from cocaine (Lu et al., 2003). Here we examined surface GluA1 and GluA2 expression, as this measure likely aligns closely with physiological measures. Finally, as cocaine and alcohol consumption downregulate, while Cef and $\mathrm{N}$-acetylcysteine upregulate both xCT and GLT-1 expression (Knackstedt et al., 2010a; Alhaddad et al., 2014; Rao and Sari, 2014), we tested the hypothesis that the expression of these proteins is coregulated. Pharmacological evidence for coregulation of these proteins has been demonstrated in cell culture (Bannai, 1986; Murphy et al., 1989), and here we are the first to investigate coregulation in vivo.

\section{Materials and Methods}

\section{Animals}

Two hundred forty-three adult male Sprague Dawley rats (Charles River Laboratories) weighing 275-300 g were single housed in a temperatureand humidity-controlled vivarium on a reversed $12 \mathrm{~h}$ light/dark cycle with water available ad libitum. Animals were food restricted to eating $20-25 \mathrm{~g}$ of standard rat chow per day. All animal procedures were approved by the institutional animal care and use committee of the University of Florida (Experiments 1-6) or the University of North Carolina, Chapel Hill (Experiment 7) and were performed in accordance with the Guide for the Care and Use of Laboratory Animals.

\section{Catheter and stereotaxic surgery}

Animals were anesthetized using a mixture of ketamine $(87.5 \mathrm{mg} / \mathrm{kg}$, i.p. $)$ and xylazine (5 mg/kg, i.p.) and surgically implanted with jugular vein catheters. Ketorolac ( $2 \mathrm{mg} / \mathrm{kg}$, i.p.) was administered preoperatively for pain. Catheters (SILASTIC silicon tubing [inner diameter (i.d.), 0.51 $\mathrm{mm}$; outer diameter, $0.94 \mathrm{~mm}$, Dow Corning] were implanted in the right jugular vein, secured with sutures, and then passed subcutaneously between the shoulder blades to exit though the skin on the back. The catheter was then attached to a stainless steel cannula that was held stable within a harness (Instech). For the implantation of guide cannulae, rats were placed in a stereotaxic frame (Stoelting), and stainless steel guide cannulae for antisense infusion (26 gauge; Plastics One) or microdialysis (22 gauge; Synaptech) were aimed at the NAc according to the following coordinates (anteroposterior, $+1.2 \mathrm{~mm}$; mediolateral, $\pm 1.6 \mathrm{~mm}$; dorsoventral, $-5.5 \mathrm{~mm}$; Paxinos and Watson, 2005). Cannulae were secured to the skull with stainless steel skull screws and dental acrylic (Co-Oral-Ite Dental MFG). Animals received $0.3 \mathrm{ml}$ of ketorolac ( $2 \mathrm{mg} / \mathrm{kg}$, i.p.) for $3 \mathrm{~d}$ postoperatively for treatment of pain. The antibiotic cefazolin $(100 \mathrm{mg} /$ $\mathrm{ml}$ ) was administered via catheter for $7 \mathrm{~d}$ and followed by $0.1 \mathrm{ml}$ of heparinized saline (Sal; $100 \mathrm{U} / \mathrm{ml})$. Catheters were flushed with $0.1 \mathrm{ml}$ of heparinized saline $(100 \mathrm{U} / \mathrm{ml})$ before and after each self-administration session to ensure continued catheter patency. Animals were allowed to recover for $5 \mathrm{~d}$ before self-administration procedures were initiated. Catheter patency was verified periodically via methohexital sodium $(10 \mathrm{mg} / \mathrm{ml}$; Eli Lilly).

\section{Cocaine self-administration and extinction procedures}

Animals were trained to self-administer cocaine under an FR-1 schedule of reinforcement in standard operant chambers $(30 \times 24 \times 30 \mathrm{~cm}$; Med Associates) equipped with two retractable levers. Presses on the active lever resulted in an intravenous infusion of cocaine $(0.33 \mathrm{mg} /$ infusion for Experiments 1-3,6; $0.2 \mathrm{mg}$ /infusion for Experiment 7), and the presentation of auditory (2900 Hz tone) and visual (stimulus light) cues. Cocaine hydrochloride was generously donated by the National Institute on Drug Abuse Controlled Substances Program (Research Triangle Institute). Each infusion of cocaine was followed by a $20 \mathrm{~s}$ "time-out" period, during which time presses on the active lever did not yield drug. Presses on the inactive lever were recorded but not reinforced. Animals maintained daily $2 \mathrm{~h}$ self-administration sessions until a criterion of $\geq 10$ infusions of cocaine/session for $12 \mathrm{~d}$ was attained. Upon reaching the criterion, animals began extinction training, during which time presses on the lever that previously yielded cocaine and cues no longer did so. During extinction training, some rats were treated with Cef $(200 \mathrm{mg} / \mathrm{kg}$, i.p.) or vehicle (Veh; $0.9 \%$ physiological saline, $1 \mathrm{ml} / \mathrm{kg}$, i.p.) and Morpholino oligos, as described below for each experiment.

\section{Antisense-mediated knockdown of GLT-1 and XCT}

Antisense Vivo-Morpholino oligos (Gene Tools) were designed to interfere with the translation of xCT and GLT-1 using sequences described previously (Reissner et al., 2012). The GLT-1 oligo was designed against a sequence that would knock down all isoforms of GLT-1, which differ by 

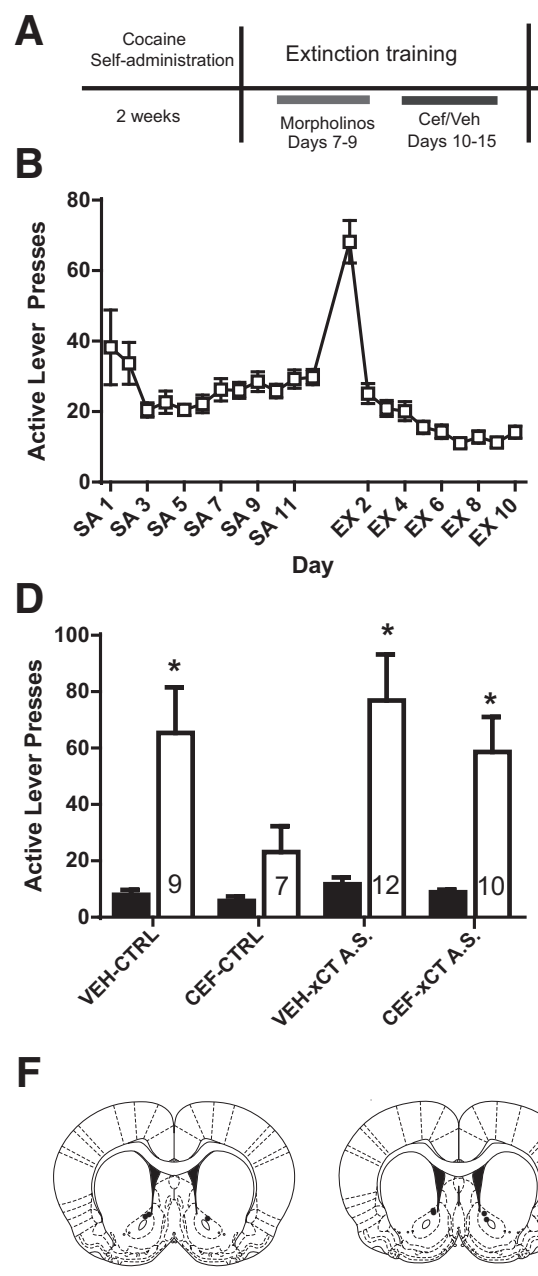

1.32

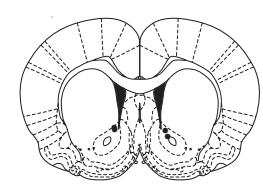

1.44

\section{Reinstatement test (Figs $1 \&$ 2) No test, euthanasia (Fig. 3) \\ Day 16}

C

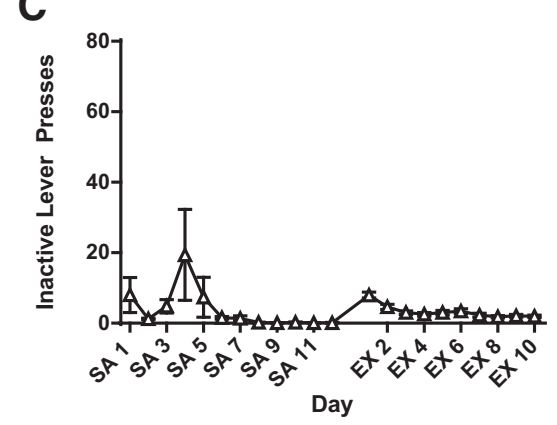

E



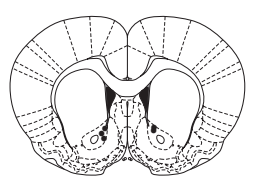

1.68
Figure 1. Self-administration, extinction, and reinstatement lever pressing in rats receiving intranucleus accumbens core AS directed at xCT or Ctrl oligo and Cef or Veh. $\boldsymbol{A}$, Timeline for the experiments yielding the data graphed in Figures 1, 2, and 3. B, Active lever presses during self-administration and extinction. $\boldsymbol{C}$, Inactive lever pressing during self-administration and extinction. $\boldsymbol{D}$, Active lever pressing during the last $2 \mathrm{~d}$ of extinction (mean) and during a cue-primed reinstatement test. Reinstatement of cocaine seeking is defined as a significant increase in active lever pressing from extinction to test. The knockdown of xCT blocked the ability of Cef to prevent reinstatement. ${ }^{*} p<0.05$ comparing extinction to cue test $(n=7-12 /$ group, indicated in $\boldsymbol{D})$. $\boldsymbol{E}$, Inactive lever presses did not differ by group or test. $\boldsymbol{F}$, A subset of the correct placements are noted here as examples of the total of 40 bilateral cannulae locations.

C-terminal sequence. A negative control (Ctrl) oligo was used with the following sequence: CCTCTTACCTCAGTTACAATTTATA. All oligos were diluted with sterile PBS and injected bilaterally at a concentration of $30 \mathrm{pmol} / \mathrm{side}$ in $1 \mu \mathrm{l}$. For microinjections, 33 gauge microinjectors (Plastics One) extended $2 \mathrm{~mm}$ beyond the tip of the cannulae, and injections were administered at the rate of $0.5 \mu \mathrm{l} / \mathrm{min}$ using an infusion pump (Harvard Apparatus). Injections occurred daily for $3 \mathrm{~d}$, ending precisely $7 \mathrm{~d}$ before the reinstatement test or being killed (Fig. 1A). Previous data showed that maximal xCT and GLT-1 downregulation occurred at this time after this injection regimen (Reissner et al., 2012).

\section{Histology}

Accurate cannulae placement was confirmed for Experiments 1, 2, and 5 using cresyl violet staining following trans-cardial perfusion with $0.9 \%$ saline. The brains were removed and stored in 10\% formalin for at least $24 \mathrm{~h}$. Coronal sections (200 $\mu \mathrm{m}$ thick) were mounted on slides and stained with cresyl violet. Cannulae placement was determined using a rat brain atlas (Paxinos and Watson, 2007). Only rats with cannulae placement inside the NAc are included in the data presented here.



1.92

\section{Experimental procedures}

Experiments 1 and 2. Rats self-administered cocaine as described above. During extinction training, rats received bilateral intra-NAc infusions of antisense targeting xCT, GLT-1, or control oligo as described above. Rats received either Cef or Veh immediately after extinction sessions for the last $6 \mathrm{~d}$ of extinction training before cue-primed reinstatement testing according to the timeline in Figure $1 A$. Rats that did not extinguish lever pressing by $7 \mathrm{~d}$ following the last morpholino infusion were not tested for reinstatement. Successful extinction was defined as an average of $<20$ presses on the previously active lever for the 2 days immediately preceding reinstatement testing. During cue-primed reinstatement tests, presses on the previously active lever once again yielded the discrete cues paired with drug delivery but no drug. Rats received a single $2 \mathrm{~h}$ reinstatement session. Outliers and rats excluded for not meeting selfadministration or extinction criteria are detailed in the Results section.

Experiments 3 and 4: surface receptor and total protein assessment of GluA1, GluA2, xCT, and GLT-1 following $x$ CT or GLT-1 antisense infusion. For Experiment 3, rats underwent cocaine self-administration. During extinction training, rats received bilateral intra-NAc infusions of antisense targeting $\mathrm{xCT}$, GLT-1, or control antisense as described above and in Figure 1A. Rats received either Cef or Veh immediately after extinction sessions for the last $6 \mathrm{~d}$ of extinction training before being killed for biotinylation/Western blotting without a reinstatement test (Fig. 1A). For Experiment 4, cocaine-naive rats received intra-NAc infusions of XCT or GLT-1 antisense or control oligos and were killed $7 \mathrm{~d}$ after the last antisense infusion.

We conducted biotinylation of surface proteins as reported previously (Knackstedt et al., 2010b). Rats were killed via rapid decapitation, and the NAc was dissected on ice and sliced with a McIllwain tissue chopper (Ted Pella). In Experiment 4, the presence of cannula tracks in acute NAc slices was visually verified. Slices were incubated in Sulfo-NHS-SS-Biotin (1 $\mathrm{mg} / \mathrm{ml}$; Pierce), and the reaction was quenched by glycine. A portion of the sample lysate was incubated with streptavidin agarose beads (ThermoFisher Scientific). The remainder of the sample was stored as the total protein fraction. Biotinylated proteins attached to streptavidin-coated beads were separated by centrifugation and eluted with Laemmli buffer. We were limited to the processing of 12 samples/day. Because the conditions (e.g., biotin lot number) could potentially affect the degree of biotinylation, 4-5 Sal-Veh-Ctrl rats were included in each biotinylation cohort for the standardization of Western blot results against this group. The amount of GluA1 and GluA2 protein in the total and biotinylation fractions was analyzed by quantitative Western blotting as described below. GLT-1, GLT-1a, and xCT were blotted only in the total protein fraction.

Proteins were separated using 10\% SDS-PAGE and transferred to PVDF membrane. The membranes were probed overnight at $4^{\circ} \mathrm{C}$ with primary antibodies diluted in $5 \%$ milk/Tris-buffered saline with $0.1 \%$ Tween-20. After incubation with HRP-conjugated secondary antiserum (Jackson Immunoresearch), immunoreactive bands on the membranes were detected by enhanced chemiluminescence (ECL Plus, GE Healthcare Bio-Sciences). Band density was measured using ImageJ software (National Institutes of Health). For total protein expression, blots were 
Table 1. Antibodies used for western blotting

\begin{tabular}{|c|c|c|c|c|c|}
\hline Antibody & Company & Catalog number & Lot number & Concentration & RRID \\
\hline Rabbit anti-Calnexin & Millipore & AB2301 & 2587261 & $1: 40000$ & $A B \_11210810$ \\
\hline Rabbit anti beta-tubulin & Abcam & $a b 6046$ & GR251141-1 & $1: 80000$ & AB_2210370 \\
\hline Guinea Pig anti-GLT1a & Millipore & AB1783 & 2234155 & $1: 20000$ & AB_90949 \\
\hline Rabbit anti-GLT1b & Paul Rosenberg, Harvard & & & $1: 50000$ & \\
\hline Rabbit anti-nGLT1 & Paul Rosenberg, Harvard & & & $1: 2000$ & \\
\hline Rabbit anti-GLT1a & Paul Rosenberg, Harvard & & & $1: 80000$ & \\
\hline Rabbit anti-xCT & Novus & NB300-318 & $\mathrm{I}-01$ & $1: 5000$ & AB_10000581 \\
\hline Mouse anti-GluA1 & Millipore & MAB2263 & 2428724 & $1: 2000$ & AB_1977459 \\
\hline Rabbit anti-GluA2 & Abcam & ab20673 & GR117410-1 & $1: 2000$ & AB_2232655 \\
\hline Rabbit anti- $\alpha 3$ & Abcam & ab2826 & GR256755-6 & 1:3000 & AB_2258740 \\
\hline
\end{tabular}

reprobed with calnexin as a loading control. Antibodies and dilutions are presented in Table 1.

Experiment 5: no-net-flux microdialysis and HPLC assessment of basal extracellular glutamate following $x C T$ knockdown in cocaine-naive rats. Cocaine-naive rats were used to determine whether $\mathrm{xCT}$ antisense altered basal extracellular glutamate in the NAc. Seven days following the last injection of Ctrl $(n=8)$ or xCT antisense $(n=9)$, microdialysis probes ( $2 \mathrm{~mm}$ cuprophane membranes, Synaptech) were implanted into the NAc. Probes were perfused overnight with aCSF containing $125 \mathrm{~mm}$ $\mathrm{NaCl}, 2.5 \mathrm{~mm} \mathrm{KCl}, 1 \mathrm{~mm} \mathrm{MgCl} 6 \mathrm{H}_{2} \mathrm{O}, 5 \mathrm{~mm}$-glucose, and $1.2 \mathrm{~mm}$ $\mathrm{CaCl}_{2} \mathrm{H}_{2} \mathrm{O}$ in $0.75 \mathrm{ml}$ of PBS. For no-net flux dialysis, increasing concentrations of glutamate $(0,2.5,5$, and $10 \mu \mathrm{M})$ were perfused and the efflux was collected at $20 \mathrm{~min}$ intervals for $80 \mathrm{~min}$. Liquid switches were used to minimize the pressure fluctuations while changing buffers. The first sample collected after switching to a new glutamate concentration was discarded.

Glutamate was quantified in dialysate samples using isocratic highperformance liquid chromatography (HPLC) with electrochemical detection (ThermoFisher Scientific). Microdialysis samples were derivatized with $o$-pthalaldehyde (Sigma-Aldrich) by an autosampler (ThermoFisher Scientific) immediately before injection onto a CAPLCELL PAK C18 column ( $5 \mu \mathrm{m}, 2.0 \mathrm{~mm}$ i.d., $\times 50 \mathrm{~mm}$; Shiseido). The mobile phase consisted of $100 \mathrm{~mm}$ $\mathrm{Na}_{2} \mathrm{HPO}_{4}, 16 \%(\mathrm{v} / \mathrm{v})$ methanol, and $2.5 \%(\mathrm{v} / \mathrm{v})$ acetonitrile, $\mathrm{pH}$ 6.5. Glutamate levels in the dialysis samples were quantified by comparing computer-integrated peak areas of samples with those of $\mathrm{L}$-glutamate standards.

Experiment 6: RT-PCR assessment of GLT-1 and xCT following cocaine self-administration and ceftriaxone treatment. Rats underwent cocaine self-administration and extinction training as described above. Following 2 weeks of extinction training, rats were killed via rapid decapitation and the NAc was dissected and frozen at $-80^{\circ} \mathrm{C}$. One hemisphere was used for quantitative PCR ( $\mathrm{PPCR}$ ) analysis, and the other for Western blotting. For qPCR, total RNA was extracted from tissue using the RNeasy Mini Kit (Qiagen) according to manufacturer instructions. The cDNA was synthesized using a High-Capacity cDNA Reverse Transcription Kit (Applied Biosystems) using $10 \mu$ l of total RNA. The SYBR-Green primer pairs were pooled and diluted to a final concentration of $200 \mathrm{nM}$ and were combined with SYBR-Green Master Mix (Applied Biosystems) and cDNA for the preamplification PCR. The PCR cycles were as follows: 1 cycle of denaturing at $95^{\circ} \mathrm{C}$ for $10 \mathrm{~min}$, then 14 cycles at $95^{\circ} \mathrm{C}$ for $15 \mathrm{~s}$ and annealing at $60^{\circ} \mathrm{C}$ for $1 \mathrm{~min}$. Preamplified samples were diluted and stored at $-20^{\circ} \mathrm{C}$. SYBR-Green Quantitative RT-PCRs were performed in triplicate on a SteponePlus machine (Applied Biosystems). For each reaction, $3 \mu \mathrm{l}$ of cDNA (1:5 diluted) was placed in a $20 \mu \mathrm{l}$ reaction containing $10 \mu \mathrm{l}$ of SYBR-Green PCR Master Mix (Applied Biosystems) and 200 nM final concentration of each primer (ThermoFisher Scientific). The primers used were previously described (O'Donovan et al., 2015) and are shown in Table 2. Reactions were performed with an initial ramp time of $3 \mathrm{~min}$ at $95^{\circ} \mathrm{C}$, and $50-60$ subsequent cycles of $15 \mathrm{~s}$ were performed at $95^{\circ} \mathrm{C}$ and for $1 \mathrm{~min}$ at the annealing temperature of $59^{\circ} \mathrm{C}$. In all, 60 cycles were used for GLT-1b, and 50 cycles were used for all other primer sets. For negative controls for the quantitative RT-PCRs, cDNA was omitted. Relative concentrations of the transcripts of interest were calculated with comparison to a standard curve made with dilutions of cDNA from a pooled sampling of all the subjects. Values for the transcripts of interest
Table 2. SYBR-Green primer sequences

\begin{tabular}{lll}
\hline Primer & Forward & Reverse \\
\hline$\beta$-actin & AGTACTCTGTGTGGATGGGT & GCTGATCCACATCTGCTGGA \\
185 & CGCGGCTAGAGGTGAATTC & TTGGCAAATGCTTCGCTC \\
cyclophilinA & CTCCTTGAGCTGTTTGCAG & CACCACATGCTTGCCATCC \\
GAPDH & GACATGCCGCCTGGAGAAACC & GACAATGAATATGGCTACAGC \\
GLT-1 & CCAGTGCTGGAACTTGCCT & TAAAGGGTGTACCATCCAT \\
GLT-1b & GGACAGGATGAGAACTTCAGTCAA & ACAAGTCTCGATATCCATGAATGG \\
xCT & CCCAGATATGCATCGTCCTT & ACAACCATGAAGAGGCAGGT \\
\hline
\end{tabular}

were normalized to the geometric mean of $18 \mathrm{~s}, \beta$-actin, GAPDH, and cyclophilin A values for the same samples. Western blotting was conducted in the second hemisphere for xCT, GLT-1a, and GLT-1b as described above for Experiments 3 and 4. Antibody concentrations are detailed in Table 1.

Experiment 7: coimmunoprecipitation of GLT-1. Animals were rapidly decapitated, and bilateral NAc tissue was dissected on ice. Tissue was homogenized in $400 \mu$ l of homogenization buffer containing $20 \mathrm{~mm}$ Tris $\mathrm{Cl}, \mathrm{pH} 7.4,140 \mathrm{~mm} \mathrm{NaCl}, 1 \%$ Triton X-100, and 1:100 protease inhibitor cocktail with EDTA (catalog \#1862209, ThermoFisher Scientific). Samples were homogenized using a sonicator, using two $5 \mathrm{~s}$ pulses. Lysates were centrifuged at $1000 \times g$ for $10 \mathrm{~min}$, and protein content was determined by BCA assay (ThermoFisher Scientific). Protein A/G agarose (catalog \#20421, ThermoFisher Scientific) was equilibrated in homogenization buffer, and $1.2 \mathrm{mg}$ of lysate was precleared for $1 \mathrm{~h}$ at $4^{\circ} \mathrm{C}$ in a final volume of $500 \mu \mathrm{l}$ containing $50 \%$ protein $\mathrm{A} / \mathrm{G}$ agarose. Precleared lysate $(500 \mu \mathrm{g})$ was then added to $10 \mu \mathrm{g}$ of antibody (either anti-GLT-1 (cata$\log \#$ ABN102, EMD Millipore) or negative control rabbit IgG (catalog \#10500C, Life Technologies) and conjugated overnight at $4^{\circ} \mathrm{C}$ with gentle rotation. The next day, $100 \mu \mathrm{l}$ of $50 \%$ beads equilibrated in homogenization buffer was added to each tube and rotated for $2 \mathrm{~h}$ at $4^{\circ} \mathrm{C}$. Beads were then washed three times in homogenization buffer plus protease inhibitors, and samples were eluted in $35 \mu \mathrm{l}$ of $4 \times$ Laemmli protein sample buffer containing $5 \% \beta$-mercaptoethanol and heated at $100^{\circ} \mathrm{C}$ for $10 \mathrm{~min}$ followed by vortexing. Eluted samples were separated from beads by centrifugation and stored at $-20^{\circ} \mathrm{C}$. Western blotting for $\mathrm{Na}^{+} / \mathrm{K}^{+}$ATPase subunit $\alpha 3$, GLT-1, and $\mathrm{xCT}$ was conducted as described above and in Table 1.

\section{Statistical analysis}

GraphPad Prism (version 6.00, GraphPad Software) was used for statistical analyses with the $\alpha$ level set at $p \leq 0.05$. Active and inactive lever pressing during self-administration and extinction training was analyzed with mixed-factorial two-way ANOVAs, with group and time as factors, and repeated-measures (RM) ANOVA conducted on time. Active and inactive lever pressing during reinstatement tests were analyzed with mixed-factorial group $\times$ test two-way ANOVAs, with group and test as factors and repeated-measures ANOVA conducted on test. Significant main effects and interactions detected by two-way RM ANOVAs were followed by Sidak's post hoc analyses to examine differences in group or time/test. Immunoblotting data, represented by integrated density of individual protein bands, was normalized for the density of calnexin 
immunoreactivity within the same sample. The treatment groups were normalized to the Sal-Veh-Ctrl group, and this value was compared between groups using one-way ANOVAs and Sidak's post hoc tests. For the no-net-flux microdialysis experiment, we first subtracted the concentration of Glu added to the perfusate from the amount measured in the dialysate ([Glu]in - [Glu] out). These values were plotted against the [Glu] in, and a line of regression was drawn. The $x$-intercept reflects basal glutamate concentration, and we examined group differences in this measure using an independent-samples $t$ test. The slope of the line of regression reflects the extraction fraction, and thus the slopes were compared between groups using an independent-samples $t$ test. PCR data were tested for normal distribution using the D'Agostino and Pearson omnibus normality test. Data were analyzed using one-way ANOVA and presented as the mean \pm SEM.

\section{Results}

\section{Cocaine self-administration}

For all experiments, assignments to receive antisense and Cef or Veh were made following the completion of self-administration such that there were no group differences in the number of infusions, or inactive and active lever presses throughout selfadministration. A number of rats were eliminated during the self-administration portion of the experiment due to a loss of catheter patency $(n=6)$, illness $(n=2)$, or failure to acquire self-administration $(n=19)$. Four rats were excluded for cannulae placements outside of the NAc (two rats each in Experiment 1 and Experiment 2), and three rats were excluded for failing to meet extinction criteria (Experiment 1). One rat was excluded due to a preference for the inactive lever over the active lever throughout self-administration (Experiment 3), and one rat displayed active lever pressing during reinstatement that was $>2$ SDs from the mean (Experiment 1). There were four outliers in Experiment 5 that are described below. Data from the remaining 203 rats are included in the results below, and the number of rats/group are detailed in the figures.

\section{Experiment 1: xCT knockdown inhibits the prevention of reinstatement by ceftriaxone}

Rats self-administered cocaine for $12 \mathrm{~d}$ and then underwent extinction training. Following 1 week of extinction training, rats were treated with a Ctrl oligo or AS oligo designed to knock down $\mathrm{xCT}$ such that the target protein would be suppressed on reinstatement day, as optimized previously (Reissner et al., 2012). Rats were also treated with Veh or Cef, according to the timeline in Figure $1 A$. Presses on the previously active lever increased on day 1 of extinction and then decreased over the course of extinction training (Fig. $1 B$ ). Presses on the inactive lever remained low throughout self-administration and extinction (Fig. 1C).

A two-way RM ANOVA conducted on active lever pressing during the last $2 \mathrm{~d}$ of extinction and the cue-primed reinstatement test indicated a significant effect of test $\left(F_{(1,35)}=43.15, p<\right.$ $0.001)$ but no effect of group and no test $\times$ group interaction. As the definition of "reinstatement" is the resumption of extinguished responding and a significant effect of test was detected, post hoc tests were conducted within each group comparing lever pressing during extinction to that during test. All groups significantly reinstated lever pressing (Veh-Ctrl, $p<0.01$; Cef-xCT AS, $p<0.01$; Veh-xCT AS, $p<0.0001$ ) with the exception of the Cef-Ctrl group (Fig. 1D), indicating that the knockdown of $\mathrm{xCT}$ inhibits Cef from preventing reinstatement. As there was not a significant test $\times$ group interaction for the data presented in Figure $1 D$, we were not able to conclude that the lever pressing during the cue-primed test was attenuated in the Cef-Ctrl group relative to presses during this test in other groups. However, as reinstatement of the drug-seeking response did not occur in CefCtrl rats (no difference between extinction and test), but did in the other three groups, our interpretation is that Cef prevents reinstatement. Rats did not increase responding on the inactive lever during the reinstatement test, as no effect of test and no group $\times$ test interaction were detected (Fig. $1 E$ ). Figure $1 F$ indicates the unilateral cannulae placement for a subset of the 40 rats used for this experiment.

\section{Experiment 2: GLT-1 knockdown inhibits the prevention of reinstatement by ceftriaxone}

Rats self-administered cocaine and underwent extinction training and treatment with Cef or Veh as in Experiment 1 (Fig. 1A). For Experiment 2, rats were infused with either Ctrl oligo or antisense designed to prevent GLT-1 translation and administered either Cef or Veh for $5 \mathrm{~d}$. Before treatment, no group differences in active lever pressing were present during self-administration (Fig. $2 A$ ). Presses on the inactive lever remained low throughout selfadministration and extinction (Fig. 2B).

A two-way RM ANOVA conducted on active lever pressing during extinction and the cue-primed reinstatement test (Fig. $2 C)$ indicated a significant effect of test $\left(F_{(1,24)}=58.73, p<\right.$ $0.0001)$, group $\left(F_{(3,24)}=4.849, p=0.0089\right)$, and a test $\times$ group interaction $\left(F_{(3,24)}=6.053, p=0.0032\right)$. Post hoc tests comparing extinction to test revealed that all groups significantly reinstated lever pressing (Veh-Ctrl, $p<0.001$; Cef-GLT AS, $p<0.01$; VehGLT AS, $p<0.001$ ) with the exception of the Cef-Ctrl group (Fig. $2 C$ ), indicating that the knockdown of xCT inhibits Cef from preventing reinstatement. Post hoc tests indicated that the CefCtrl group displayed a significantly lower number of active lever presses during the test than the Veh-Ctrl $(p<0.001)$, Veh-GLT AS $(p<0.0001)$, and Cef-GLT AS $(p<0.01)$ groups. A significant effect of test $\left(F_{(1,24)}=6.967, p=0.0144\right)$ was detected for inactive lever pressing, as there was an overall decrease in inactive lever pressing from extinction to test; however, post hoc tests did not reveal differences between extinction and test for any group (Fig. 2D).

\section{Experiment 3: surface and total expression of glutamate receptors and transporters following GLT-1 or xCT knockdown}

To understand the potentially distinct NAc adaptations underlying the ability of xCT and GLT-1 knockdown to prevent Cef from attenuating reinstatement, we assessed protein expression of GLT-1, xCT, and the AMPA receptor subunits GluA1 and GluA2 in a separate cohort of rats treated identically to those in Experiments 1 and 2. No group differences in active lever pressing were found during self-administration or extinction (Fig. $3 A$ ). While the number of inactive lever presses was high on day 1 of self-administration, the number declined and remained low throughout self-administration and extinction training (Fig. 3B). According to the timeline in Figure $1 A$, rats did not undergo a reinstatement test but were killed via rapid decapitation without anesthesia, the NAc was rapidly dissected, and surface and total protein fractions were labeled and separated by surface biotinylation. GLT-1 and xCT were blotted in the total fraction to confirm the ability of antisense treatment to decrease GLT-1 and xCT expression in rats receiving long-term ceftriaxone treatment. We blotted for the GLT-1a splice variant as this is the predominant isoform expressed in the rodent forebrain (Rimmele and Rosenberg, 2016) and was previously shown to be upregulated by Cef (Rothstein et al., 2005). We also used an antibody that detects both GLT-1a and GLT-1b splice variants by recognizing an epitope on the shared $\mathrm{N}$ terminus; we report these results as 
"nGLT-1." GluA1 and GluA2 were blotted in both total and surface fractions as GluA1 surface (but not total) expression is increased by cocaine self-administration while GluA2 is not, indicating the formation of GluA2-lacking AMPA receptors (Conrad et al., 2008).

GLT-1a expression in the total protein fraction differed by group $\left(F_{(4,39)}=6.886\right.$, $p=0.0003$; Figure $3 C$ ). The Coc-Veh-Ctrl group displayed reduced GLT-1a expression compared with the Sal-VehCtrl group $(p<0.05)$, confirming our previous findings that cocaine self-administration reduces GLT-1 expression in the NAc (Knackstedt et al., 2010a). The Coc-Cef-GLT-1 AS group also demonstrated significantly reduced GLT-1a relative to Sal $(p<0.05)$, indicating that the knockdown of GLT-1 in the presence of Cef treatment knocked down the GLT-1a isoform. The Coc-Cef-xCT AS group displayed reduced GLT-1a expression relative to both the Sal $(p<0.001)$ and the Coc-Cef-Ctrl $(p<0.01)$ groups, and so the knockdown of xCT significantly reduced GLT-1a expression. The pattern of nGLT-1 expression (data not shown) was identical to that of GLT-1a, with expression differing by group $\left(F_{(4,34)}=7.309\right.$, $p=0.0002)$. The Coc-Cef-GLT-1 AS group displayed reduced nGLT-1 relative to Sal $(p<0.05)$, indicating that the knockdown of GLT-1 in the presence of Cef treatment was effective. The Coc-CefxCT AS group displayed reduced nGLT-1 expression relative to both the Sal $(p<$ $0.001)$ and the Coc-Cef-Ctrl $(p<0.01)$ groups, and so the knockdown of xCT significantly reduced GLT-1 expression, providing evidence of coregulation of $\mathrm{xCT}$ and GLT- 1 by ceftriaxone. The identical pattern of expression between the GLT-1a and nGLT-1 isoforms supports the idea that the GLT-1a splice variant is the predominant variant in the forebrain (for review, see Danbolt et al., 2016). It is also possible that GLT-1b expression changes in the same pattern as GLT-1a. Unfortunately, we did have sufficient tissue for blotting GLT-1b in these samples after conducting the Western blotting reported here.

The expression of xCT (Fig. 3D) differed by group $\left(F_{(4,44)}=\right.$ $3.114, p=0.0243)$. Post hoc tests revealed that Coc-Cef-Ctrl rats had increased $\mathrm{xCT}$ expression relative to both the $\mathrm{Sal}(p<0.001)$ and Coc-Veh-Ctrl $(p<0.001)$ groups, and this effect was reversed by xCT antisense infusion (Coc-Cef-Ctrl vs Coc-Cef-xCT AS, $p<0.0001$ ). While the knockdown of GLT-1 did not significantly reduce $\mathrm{xCT}$ expression relative to Sal controls, it prevented Cef from upregulating $\mathrm{xCT}$, also providing evidence for the coregulation of these transporters by Cef. Rats infused with GLT- 1 antisense and administered Cef displayed xCT expression that did not differ from that in cocaine-naive rats, indicating that the reinstatement of cocaine seeking in this group (Fig. 2C) can be solely attributed to GLT-1 knockdown. Interestingly, xCT expression in the Coc-Veh-Ctrl group was not reduced $(p=0.08)$ relative to Sal controls, whereas we have previously demonstrated it to be significantly lower (Knackstedt et al., 2010a). This differ-

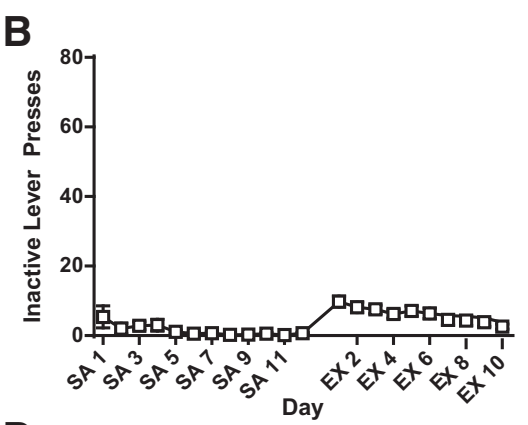

D





1.68

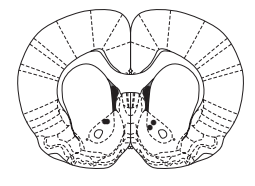

1.92



1.44



Figure 2. Self-administration, extinction, and reinstatement lever pressing in rats receiving intra-nucleus accumbens core AS directed at GLT-1 or Ctrl oligo. $\boldsymbol{A}$, Active lever presses during self-administration and extinction. $\boldsymbol{B}$, Inactive lever pressing during to cue test. $\# p<0.05$ compared to Cef-Ctrl ( $n=7 /$ group). $\boldsymbol{D}$, Inactive lever pressing. $\boldsymbol{E}$, A subset of the 28 correct placements are noted here as example cannulae placements.

ence may arise from the fact that here we blotted in total protein lysates, whereas previously we blotted for xCT in a membraneenriched fraction.

We have previously shown that Cef reduces the potentiated evoked and spontaneous EPSCs observed in the NAc following cocaine self-administration and extinction (Trantham-Davidson et al., 2012). Here, we had hypothesized that we would observe increased GluA1 and GluA2 surface expression in the NAc of rats administered cocaine that would be normalized by Cef. Surprisingly, we found only increased GluA1, but not GluA2, surface expression after cocaine administration (Fig. $3 E, F$ ), a pattern of expression that indicates the formation of GluA2-lacking, calciumpermeable (CP) AMPA receptors. A one-way ANOVA revealed a significant effect for surface GluA1 expression $\left(F_{(4,40)}=5.252, p=\right.$ 0.0017), with increased expression in the Coc-Veh-Ctrl $(p<0.01)$ and Coc-Cef-xCT AS $(p<0.05)$ groups relative to the Sal-Veh-Ctrl group, as cocaine increased surface GluA1 and Cef treatment normalized GluA1 (post hoc tests showed that this group did not differ from the Sal-Veh-Ctrl group). The ability of Cef to normalize GluA1 was prevented by xCT AS (Fig. $3 E$ ). Similar analyses of GluA1 total protein expression did not detect a group effect (data not shown), indicating that only trafficking to the membrane surface was altered by cocaine and xCT knockdown. Surface GluA2 expression differed by group $\left(F_{(4,42)}=3.518, p=0.0145\right)$, an effect driven by a significant increase in the Coc-Cef-xCT AS group relative to the Sal-Veh- 
A

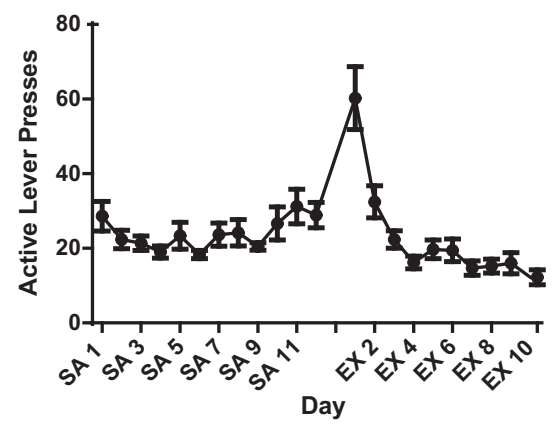

C



$\mathbf{E}$

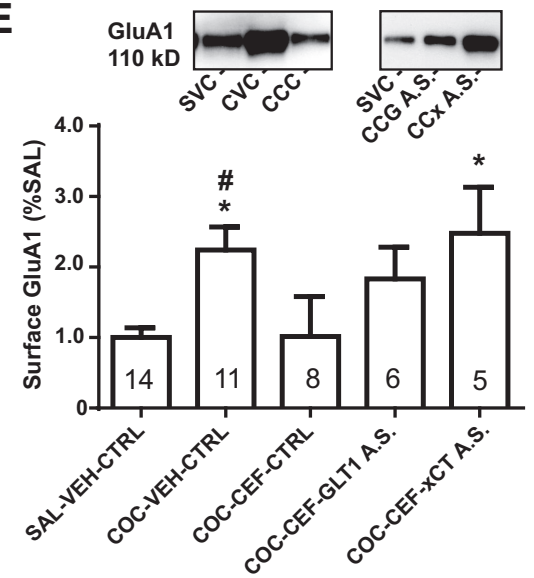

B

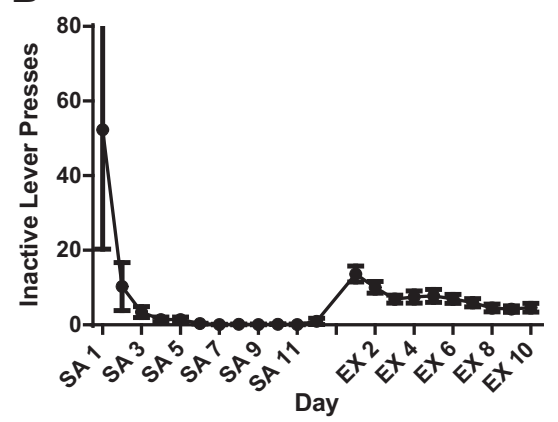

D
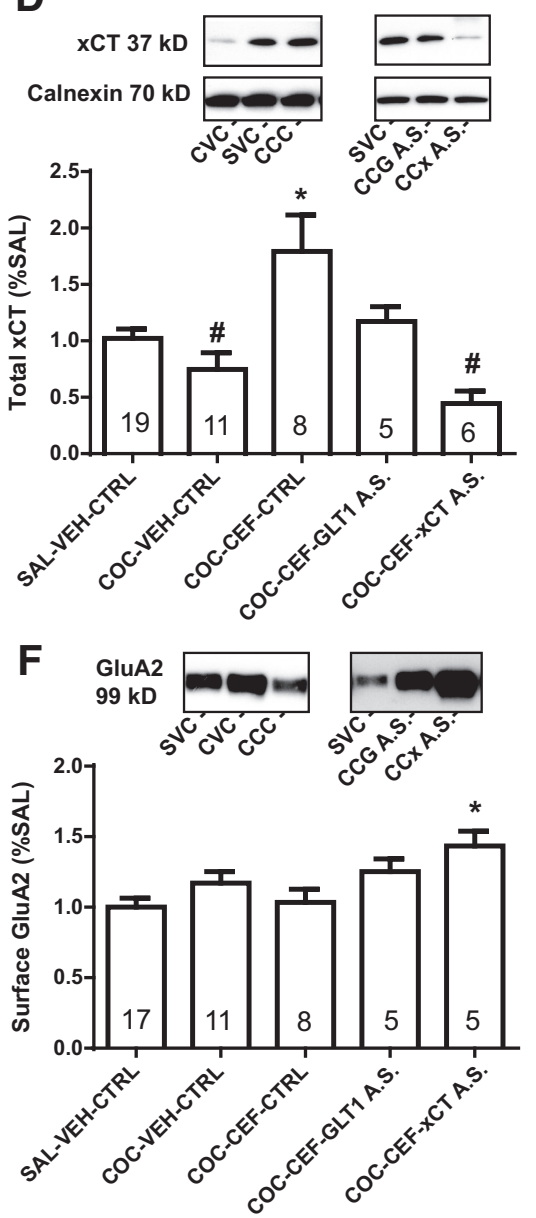

Figure 3. Surface expression of GluA1 and GluA2 and total protein expression of xCT and GLT-1. Rats self-administered Coc or received yoked-saline infusions (Sal) and were treated with either Cef or Veh during extinction training. Rats received intra-NAc AS directed at either GLT-1 or xCT or received Ctrl oligo according to the timeline in Figure $1 A$. Protein expression is expressed as a percentage of the Sal-Veh-Ctrl group. $\boldsymbol{A}$, Active lever pressing during self-administration and extinction. $\boldsymbol{B}$, Inactive lever pressing during self-administration. $\boldsymbol{C}$, Total protein expression of GLT- 1 is decreased by Coc administration and restored by Cef administration. The knockdown of both xCT and GLT-1 itself decreases the total expression of GLT-1 in Coc-Cef-treated rats. D, Total protein expression of xCT is upregulated by Cef relative to Veh-treated Coc and Sal-Veh-Ctrl rats. The knockdown of xCT and GLT-1 prevents this upregulation by Cef.E, Surface GluA1 expression was increased by cocaine and normalized by Cef. The knockdown of $x C T$ negated the ability of Cef to normalize GluA1 expression. $\boldsymbol{F}$, Surface GluA2 was unaltered by Coc, but the knockdown of $x C T$ increased GluA2 expression. ${ }^{*} p<0.05$ compared to the Sal-Veh-Ctrl group. \#p $<0.05$ compared to the Coc-Cef-Ctrl group. SVC, Sal-Veh-Ctrl; CVC, Coc-Veh-Crrl; CCC, Coc-Cef-Ctrl; CCG, Coc-Cef-GLT-1 AS; CCX, Coc-Cef-xCT AS.

Ctrl group $(p<0.05$; Fig. $3 F)$. Similar analyses on total GluA2 expression detected a group effect $\left(F_{(4,42)}=3.316, p=0.019\right.$; data not shown). Post hoc tests revealed a significant difference between the Sal-Veh-Ctrl and the Coc-Cef-Ctrl groups $(p<0.05)$, indicating that ceftriaxone administered to rats administered cocaine reduces GluA2 total protein expression. The present results provide evidence for the formation of GluA2-lacking AMPA receptors in the NAc after cocaine self-administration, an effect previously demonstrated in the NAc of rats after lengthy abstinence (without extinction) from $6 \mathrm{~h} / \mathrm{d}$ cocaine self-administration (Conrad et al., 2008). In agreement with our previous study (LaCrosse et al., 2016), Cef prevented the increase in GluA1 expression observed in rats administered cocaine. This effect was prevented by xCT but not GLT-1 antisense. Interestingly, xCT knockdown in the presence of Cef increased GluA2 surface expression, while cocaine self-administration alone had no effect on GluA2. 
A

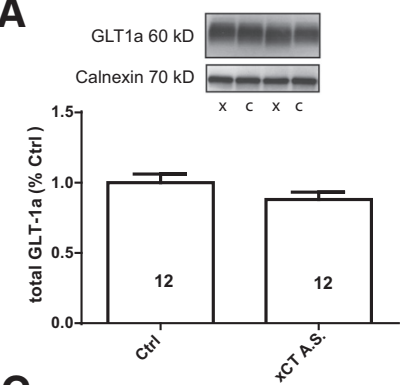

C

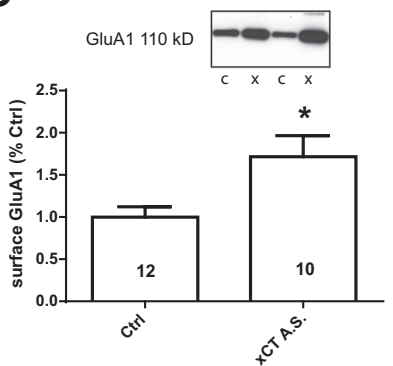

B

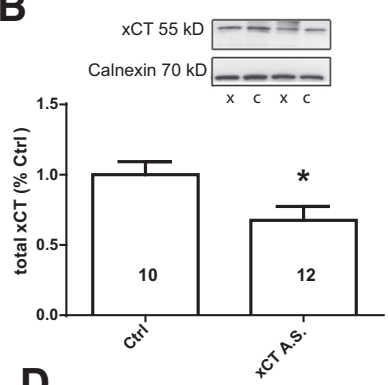

D

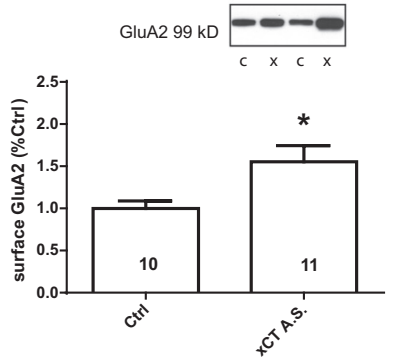

A


B
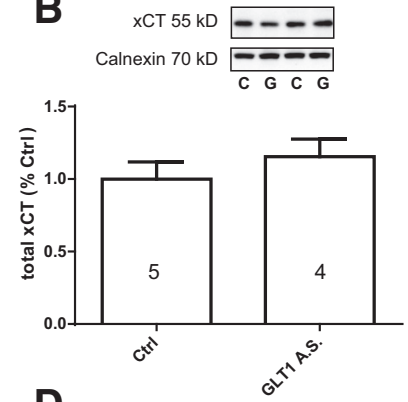

D

GluA2 99 kD

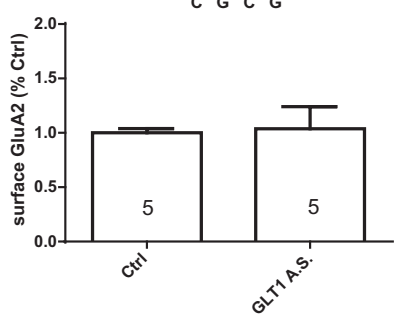

Figure 4. Surface expression of GluA1 and GluA2 and total protein expression of xCT and GLT-1. Cocaine-naive rats received intra-NAc AS directed at xCT $(n=12)$ or Ctrl oligo $(n=10)$. Protein expression was expressed as a percentage of the Ctrl group. $\boldsymbol{A}$, Overall, there was no effect of xCT knockdown on GLT-1 expression in the total protein fraction. $\boldsymbol{B}$, The infusion of xCT AS successfully reduced xCT expression. C, Surface GluA1 was increased by xCT knockdown. $\boldsymbol{D}$, Surface GluA2 was increased by xCT knockdown. ${ }^{*} p<0.05$ compared to Ctrl. C, Ctrl oligo, $x, x C T$ AS.

Experiment 4: the effects of XCT and GLT-1 knockdown on GluA1, GluA2, and GLT-1 expression in cocaine-naive rats The pattern of GluA1 and GluA2 surface expression in Figure 3 indicates that the cocaine-induced shift to GluA2-lacking AMPA receptors is not solely driven by decreased expression of $\mathrm{xCT}$ and the consequent decrease in basal glutamate levels. Furthermore, $\mathrm{xCT}$ knockdown resulted in a significant decrease in GLT-1 expression. Thus, we investigated whether xCT knockdown alone would be sufficient to reproduce these patterns of protein expression in the absence of cocaine or Cef. We infused xCT AS $(n=12)$ or Ctrl oligo $(n=12)$ in the NAc of cocaine-naive rats and conducted a biotinylation protocol on fresh NAc tissue. Total protein expression of GLT-1a was unaffected (Fig. 4A) as was expression of nGLT-1, and surface expression of GLT-1a and nGLT-1 (data not shown). In the total protein fraction, $\mathrm{xCT}$ was significantly decreased by xCT knockdown $\left(t_{(20)}=2.362, p=0.0284\right.$; Fig. $\left.4 B\right)$. Surface GluA1 expression was significantly increased by $\mathrm{xCT}$ knockdown in cocaine-naive rats $\left(_{(20)}=2.725, p=0.0130\right.$; Fig. $4 C$ ), while GluA1 in the total protein fraction was unaffected (data not shown). Similarly, surface GluA2 expression was significantly increased by $\mathrm{xCT}$ knockdown in cocaine-naive rats $\left(t_{(19)}=2.514, p=0.0211\right.$; Fig. $\left.4 D\right)$, while GluA2 in the total protein fraction was unaffected (data not shown). Thus, a reduction in $\mathrm{xCT}$ level is sufficient to increase surface expression of AMPA receptor subunits in the absence of a history of cocaine exposure but does not favor the formation of CP-AMPA receptors that lack the GluA2 subunit.

The data presented in Figure 3D indicate that while GLT-1 knockdown did not result in a significant decrease in XCT expression relative to either the Sal-Veh-Ctrl or Coc-Cef-Ctrl group, it did prevent ceftriaxone from upregulating xCT expression. Thus, we infused GLT-1 AS into the NAc of cocaine-naive rats and investigated the effects of GLT-1 knockdown on the proteins assessed in Figure 3. We found that the GLT-1 knockdown was

Figure 5. Surface expression of GluA1 and GluA2 and total protein expression of xCT and GLT-1. Cocaine-naive rats received intra-NAc AS directed at GLT-1 $(n=5)$ or Ctrl oligo $(n=5)$. Protein expression was expressed as a percentage of the Ctrl group. $\boldsymbol{A}, \mathrm{GLT}-1$ antisense decreased total protein expression of GLT-1. $\boldsymbol{B}$, The infusion of GLT-1 AS had no effect on total XCT expression. C, Surface GluA1 was not affected by GLT-1 knockdown. D, Surface GluA2 was not affected by GLT-1 knockdown. ${ }^{*} p<0.05$ compared to Ctrl. C, Ctrl oligo; G, GLT-1 AS.

effective at reducing nGLT-1 expression $\left(t_{(6)}=1.969, p=0.0482\right.$; Fig. $5 A$ ) but had no effect on total xCT expression (Fig. $5 B$ ) in drug-naive rats. Surface and total expression of GluA1 and GluA2 were not altered (Fig. 5C,D for surface expression). Together with the results in Figure 4, the coregulation of xCT and GLT-1 expression observed in Figure 3 is only observed following ceftriaxone treatment in rats with a history of cocaine exposure. It should be noted that we did not include control conditions in which cocaine-naive rats received ceftriaxone in combination with antisense directed against either GLT-1 or xCT because our previous work (Knackstedt et al., 2010a) found that cocaine-naive rats do not display changes in either protein when receiving the same regimen of ceftriaxone treatment used here. Thus, this manipulation would not be predicted to produce different results than those found here in Figures 4 and 5.

\section{Experiment 5: knockdown of xCT in the nucleus accumbens} core reduces basal glutamate levels in cocaine-naive rats In the NAc, the basal extracellular glutamate level is reduced by $60 \%$ upon infusion of Sxc inhibitors (Baker et al., 2002). Here we sought to determine whether genetic knockdown of xCT would have the same effect. Indeed, NAc basal extracellular glutamate was reduced by $\mathrm{xCT}$ antisense in cocaine-naive rats (Fig. 6B). We plotted glutamate infused into the NAc against the net flux of glutamate (Fig. 6A). Using the point of $y=0$ to determine basal glutamate levels, a decreased basal glutamate level was observed in $\mathrm{xCT}$ antisense-infused rats relative to Ctrl animals (Fig. 6B; $\left.t_{(12)}=3.226, p=0.0073\right)$. Data from one Ctrl rat was excluded for being $>2$ SDs from the average basal glutamate. A line of regression was drawn through the four points; any rat with an $r^{2}$ of $<80 \%$ was excluded (two from Ctrl group; one from xCT AS group). The slope of the regression line was significantly reduced following xCT AS infusion $\left(F_{(1,68)}=11.4177, p=0.0012\right)$, indicating a potential decrease in glutamate reuptake. Thus, while we 


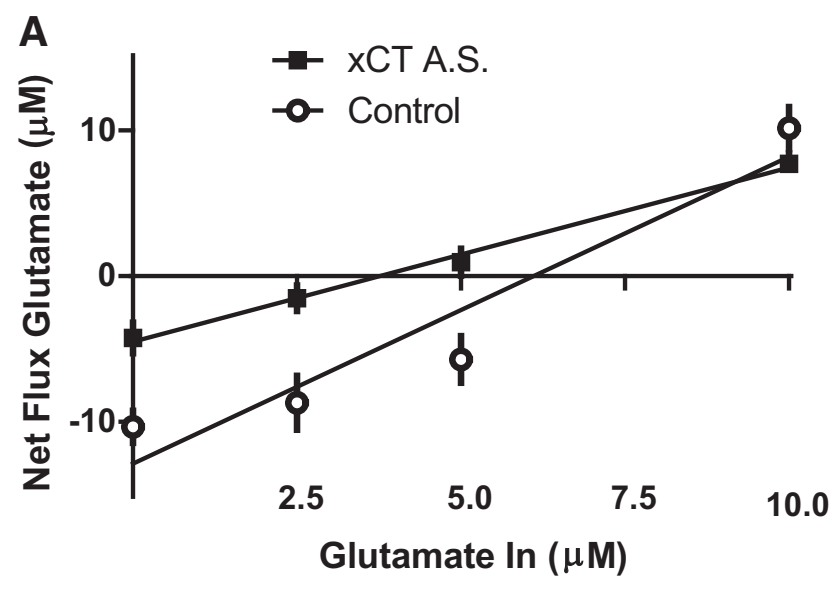

B

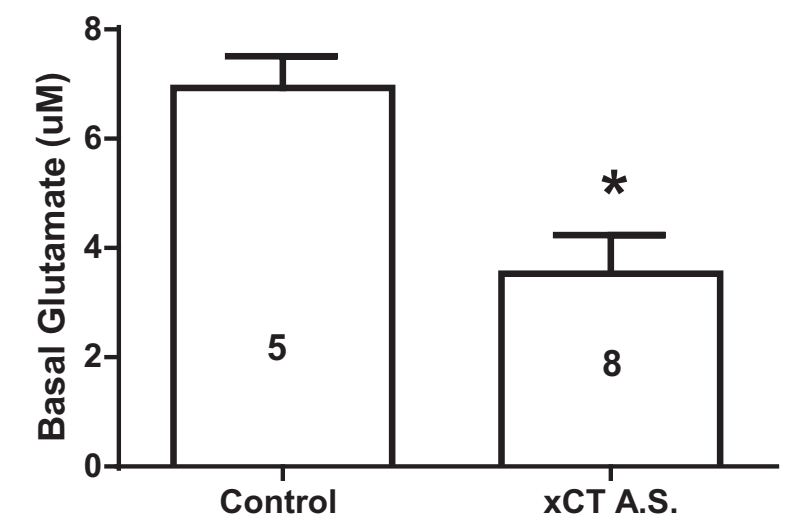

C

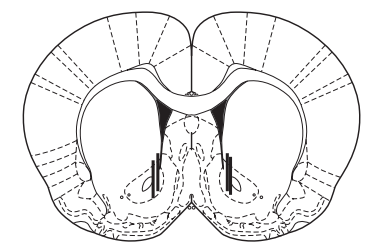

1.32

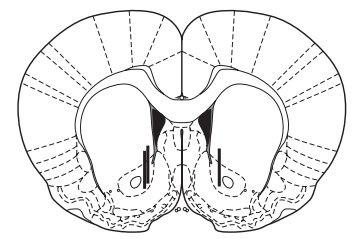

1.68

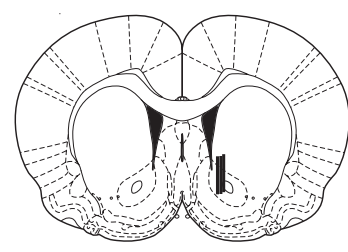

1.44

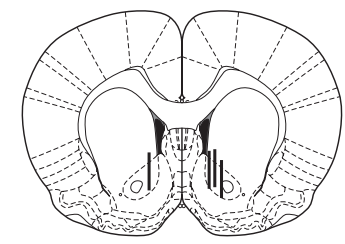

1.92

Figure 6. No-net-flux microdialysis revealed that basal extracellular glutamate is reduced by intra-NAc infusion of xCT antisense. $\boldsymbol{A}$, The concentration of glutamate perfused was plotted against the net flux of glutamate. $\boldsymbol{B}$, Computing the point of no net-flux across the dialysis membrane in $\boldsymbol{A}$ and making a comparison between groups revealed that xCT antisense significantly reduced the basal glutamate level relative to the $\mathrm{Ctrl}$ group. $C$, Microdialysis probe tracks through the NAc; representative examples of dialysis probes are depicted along the rostrocaudal axis of the NAc. * Indicates significant difference between groups $(p<0.05)$.

did not observe changes in total GLT-1 expression after $\mathrm{xCT}$ knockdown (Fig. 4A), other adaptations in the transporter may be occurring, such as changes in binding, activity, or placement in the synapse. Furthermore, we can conclude that the upregulation of GluA1 and GluA2 occurring after xCT knockdown (Fig. 4C,D) is a consequence of decreased basal glutamate levels.

Experiment 6: GLT-1 mRNA expression is not significantly altered by cocaine or ceftriaxone

The data presented in Figure 3 indicate that antisense-mediated reduction in $\mathrm{xCT}$ protein expression significantly reduces GLT-1a expression in rats treated with Cef, and antisense directed at GLT-1 reduces the ability of Cef to upregulate $\mathrm{xCT}$. However, Cef was reported to increase rodent GLT-1 (Rothstein et al., 2005) and xCT mRNA expression (Lewerenz et al., 2009) in vitro. Because the results of Figure 3 indicate a coregulation of Cef on $\mathrm{xCT}$ and GLT-1 protein expression, we investigated the effects of cocaine and Cef treatment on GLT-1 and xCT mRNA expression. Cef has been shown to increase the protein expression of two splice variants of GLT-1: GLT-1a and GLT-1b (Alhaddad et al., 2014; Rao et al., 2015). Thus, we quantified both GLT-1a and GLT-1b mRNA and protein expression here in the same animals. Rats self-administered cocaine and were treated with either Cef or Veh during extinction training, as shown in Figure $1 A$, without antisense treatment. Before assignment to receive Cef or Veh, there were no group differences in infusions (data not shown) or active lever pressing during self-administration or extinction training (Fig. 7A). Similarly, there was no effect of group on inactive lever presses during self-administration (Fig. 7B). Following rapid decapitation, the NAc was dissected, and one hemisphere was frozen for qPCR analysis and the other was frozen for Western blotting. We found no significant group effects on total GLT-1, GLT-1b, or xCT mRNA expression (Fig. 7C-E). Western blotting for GLT-1a in the total protein fraction revealed a significant overall effect of group on GLT-1a expression $\left(F_{(2,20)}=\right.$ $3.456, p=0.05$; Fig. $7 F)$. A significant effect of group on GLT-1b expression was detected $\left(F_{(2,25)}=4.127, p=0.0283\right.$, Fig. $\left.7 G\right)$. Post hoc tests revealed that the expression of GLT-1b in the SalVeh group was significantly greater than that in the Coc-Veh group $(p<0.05)$. A one-way ANOVA conducted on xCT immunoreactivity $($ Fig. $7 H$ ) revealed a significant main effect of group $\left(F_{(2,20)}=3.456, p=0.05\right)$, but post hoc tests did not reveal further differences.

Western blotting for these proteins was not conducted in samples from the Sal-Cef group, as we previously have shown that Cef is unable to increase the expression of these proteins in cocainenaive rats (Knackstedt et al., 2010a). Thus, the ability of both cocaine and Cef to alter GLT-1 and xCT protein expression potentially stems from translational and/or membrane-trafficking modifications.

Experiment 7: coregulation of $\mathrm{xCT}$ and GLT-1 is not accomplished through direct physical interaction

Both XCT and GLT-1 are downregulated following cocaine administration, and long-term treatment with Cef increases their expression. We sought to determine whether the ability of cocaine and Cef to alter the expression of both proteins is due to their physical interaction under these conditions. Thus, we treated rats that had self-administered cocaine and undergone extinction with Veh $(n=2)$ or Cef $(n=2)$ and did the same in yoked-saline rats ( $n=2$ for Veh and Cef treatment) according to the timeline in shown in Figure 1A. A GLT-1 pulldown was conducted on freshly dissected NAc tissue. Western blots against nGLT-1 confirmed that we successfully immunoprecipitated GLT-1 (Fig. 8A) and $\mathrm{Na}^{+} / \mathrm{K}^{+}$ATPase $\alpha 3$, a protein known to be physically associated with GLT-1 (Genda et al., 2011; Fig. 8B). $\mathrm{xCT}$ protein did not coimmunoprecipitate with GLT-1 under any condition (Fig. 8C), confirming our previous finding in postmortem human prefrontal cortex (Shan et al., 2014). 


\section{Discussion}

The present findings support important and distinct roles for GLT-1 and xCT in mediating the protective effects of ceftriaxone on the NAc synapse and the reinstatement of cocaine seeking. The knockdown of XCT in the NAc prevented Cef from attenuating reinstatement and from normalizing GLT-1 and GluA1 levels. Intra-NAc GLT-1 antisense also prevented Cef from attenuating reinstatement, an effect solely attributable to GLT-1 knockdown as xCT, GluA1, and GluA2 expression was not altered by GLT-1 antisense relative to controls. The knockdown of $\mathrm{xCT}$ in cocaine-naive rats reduced basal extracellular glutamate levels in the NAc and increased surface GluA1 and GluA2 expression but did not alter GLT-1 expression.

\section{Regulation of relapse to cocaine seeking by glutamate}

The reinstatement of cocaine seeking is accompanied by glutamate efflux (McFarland et al., 2003), and the infusion of an mGluR2/3 agonist into the NAc core attenuates reinstatement (Peters and Kalivas, 2006) by reducing glutamate efflux during cue-primed reinstatement (Smith et al., 2017). Reinstatement is also attenuated by intra-NAc infusions of AMPA receptor (Famous et al., 2008), CP-AMPA

(White et al., 2016), and mGlu5 receptor antagonists (Wang et al., 2013). Conversely, agonists to mGlu5 (Wang et al., 2013; Schmidt et al., 2015) and AMPA receptors induce reinstatement when infused into the NAc (Ping et al., 2008). Ceftriaxone and $\mathrm{N}$-acetylcysteine attenuate glutamate release during cocaineprimed reinstatement, an effect attributed to the ability of both compounds to increase $\mathrm{xCT}$ expression and Sxc function (Baker et al., 2003; Trantham-Davidson et al., 2012). It is hypothesized that increased nonsynaptic basal glutamate released by Sxc increases tone on the presynaptic mGluR2/3 autoreceptors so that action potential-dependent release can be regulated during the reinstatement test. It is striking that reinstatement is not just attenuated by long-term Cef treatment but is prevented (Figs. $1 D$, $2 C)$. We have replicated this effect in other ongoing, currently unpublished, studies in our laboratory. We believe that this occurs because not only does Cef attenuate presynaptic glutamate release, it also increases GLT-1 and glutamate reuptake (Knackstedt et al., 2010a; Trantham-Davidson et al., 2012) to prevent spillover of glutamate to the extrasynaptic mGlu5 receptors. Furthermore, Cef reduces EPSC amplitude (Trantham-Davidson et al., 2012) and surface GluA1 expression (Fig. 3), potentially reducing CP-AMPA formation. Thus, Cef is able to prevent reinstatement by reducing NAc medium-spiny neuron stimulation from both AMPA and mGlu5 receptors.

The present data support an essential role for GLT-1 in mediating the protective effects of Cef on reinstatement. GLT-1 likely decreases the synaptic and extrasynaptic levels of glutamate during reinstatement, limiting glutamate spillover and thus mGlu5 stimulation. We previously showed that NAc GLT-1 knockone-way ANOVA.
B
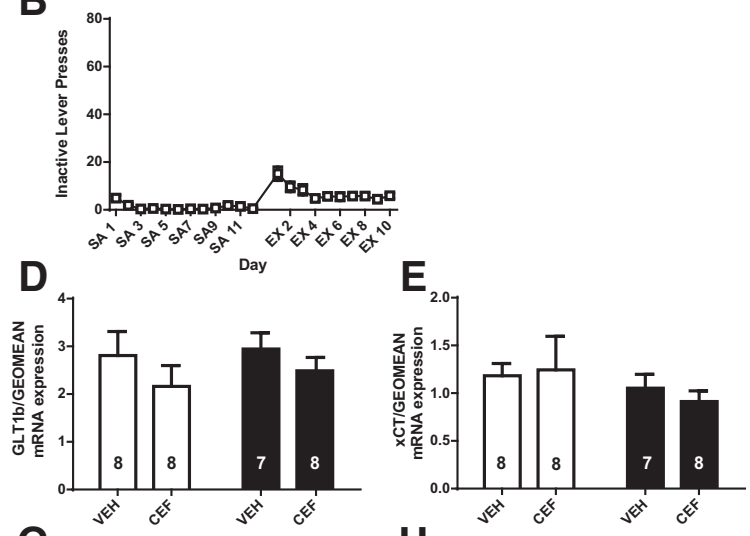

G



H

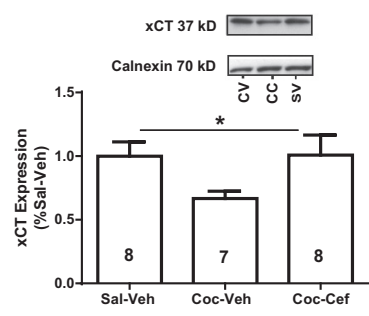

Figure 7. Nucleus accumbens core total protein and mRNA expression of GLT- 1 isoforms following cocaine self-administration and 2-3 weeks of extinction (Coc) or yoked-saline infusions (Sal). Cef or Veh treatment occurred during the last $6 \mathrm{~d}$ of extinction 作 was altered by Coc and Cef. * $p<0.05$ compared to Sal-Veh group; line with * indicates significant $(p<0.05)$ effect of group with



Figure 8. GLT-1 and xCT are not physically associated with one another in the nucleus acccumbens core after cocaine or ceftriaxone administration. Rats self-administered cocaine or received yoked saline infusions, underwent extinction training, and were treated with Veh or Cef. A GLT-1 pulldown was conducted on freshly dissected NAc tissue. $\boldsymbol{A}, \boldsymbol{B}$, Western blots against nGLT-1 confirmed that we successfully immunoprecipitated GLT-1 $(\boldsymbol{A})$ and $\mathrm{Na}{ }^{+} / \mathrm{K}^{+}$ ATPase $\alpha 3(\boldsymbol{B})$, a protein known to be physically associated with GLT-1. C, xCT protein did not immunoprecipitate with GLT-1 under any condition. Negative control, Immunoprecipitation with an irrelevant antibody; $\alpha 3$ (m), $\alpha 3$ monomer; $\alpha 3$ (d), $\alpha 3$ dimer; S-V, yoked-saline plus vehicle; $C-V$, cocaine plus vehicle; $S-C$, cocaine plus ceftriaxone; $C-C$, cocaine plus ceftriaxone.

down increases cue-primed reinstatement of cocaine seeking in $\mathrm{N}$-acetylcysteine-treated rats, an effect prevented by a subthreshold infusion of an mGlu5 receptor antagonist into the NAc (Reissner et al., 2015). Our results are also consistent with the finding that short-term intra-NAc treatment with a GLT-1 antagonist 
prevented Cef from attenuating cue-primed reinstatement (Fischer et al., 2013).

Upregulation of $\mathrm{xCT}$ by Cef is essential to the ability of Cef to attenuate reinstatement (Fig. 1). However, since xCT knockdown prevented Cef from increasing GLT-1 expression, it is not clear whether this behavioral effect is caused by decreased $\mathrm{xCT}$ or GLT-1 expression. Furthermore, xCT upregulation is necessary for Cef to reduce GluA1 surface expression, which likely contributes to the ability of Cef to prevent cue-primed reinstatement.

\section{GluA2-lacking AMPA receptor formation after cocaine self-administration}

We found increased surface GluA1 expression and no change in surface GluA2 expression following cocaine self-administration, a pattern characteristic of CP-AMPA receptor formation (Liu and Zukin, 2007). These receptors were first found after withdrawal from long-access (LgA; $6 \mathrm{~h} / \mathrm{d}$ ) cocaine self-administration without extinction (Conrad et al., 2008), and their presence in the NAc was verified by an increased rectification index (RI). This group went on to find that CP-AMPAs are found in the NAc after long withdrawal ( $>35 \mathrm{~d}$ ) from LgA but not short-access (ShA; 2 h/d) cocaine self-administration (Purgianto et al., 2013). However, when extinction training is used following ShA cocaine selfadministration, there is evidence of CP-AMPA formation: the CP-AMPA receptor antagonist Naspm attenuates cocaineprimed reinstatement when infused into the NAc (White et al., 2016). In agreement, here we find evidence for CP-AMPA formation after ShA cocaine self-administration and extinction training (Fig. $3 E, F$ ). However, evidence for increased RI following ShA self-administration and extinction training is needed to confirm CP-AMPA formation. Ceftriaxone normalized surface GluA1 expression (Fig. 3E) through an unknown mechanism. As mGluR1 stimulation decreases surface GluA1 expression (McCutcheon et al., 2011; Loweth et al., 2014), it is possible that the increase in nonsynaptic glutamate after long-term Cef treatment stimulates mGluR1 to reduce surface GluA1.

Decreasing basal glutamate levels was not sufficient to increase surface GluA1 expression relative to that of GluA2 (Figs. 4, 6). The observed increase in both AMPA receptor subunits accompanying decreased basal glutamate levels is in line with a synaptic scaling effect. Synaptic scaling involves an upregulation in GluA1 and GluA2 surface expression and increased miniature EPSC amplitude following prolonged blockade of glutamate transmission and has previously been reported in cultured cells (O'Brien et al., 1998; Sun and Wolf, 2009). We are the first to report such an effect in vivo after a manipulation to chronically reduce glutamate levels. Thus, the formation of CP-AMPAs following cocaine administration may be due to other pharmacological effects of cocaine self-administration or to extinctionrelated learning.

\section{Coregulation of $\mathrm{xCT}$ and GLT-1 expression by ceftriaxone}

GLT- 1 and $x C T$ expression is decreased in the NAc after administration of cocaine (Knackstedt et al., 2010a) and nicotine (Knackstedt et al., 2009). Ceftriaxone elevates both xCT and GLT-1 following administration of cocaine (Knackstedt et al., 2010a) and alcohol (Alhaddad et al., 2014). Evidence for functional coregulation of the transporters also exists: the depletion of intracellular glutamate inhibits Sxc export of glutamate (Bannai, 1986). In non-neuronal cells, glutamate taken up by glutamate transporters activates Sxc to export glutamate (Rimaniol et al., 2001). Excess accumulation of glutamate in the extracellular space decreases Sxc activity (Murphy et al., 1989), indicating that a homeostatic mechanism exists to balance extracellular glutamate release and reuptake. However, we found that in the absence of a history of cocaine or ceftriaxone administration, the knockdown of GLT-1 or xCT was not capable of altering the protein expression of the other protein. We found evidence for reduced glutamate clearance upon knockdown of xCT (Fig. 6), and thus it is possible that a reduction in GLT-1 function was present in this condition.

We found no evidence that Cef exerts coregulation of the transporters via a transcriptional mechanism as there was no effect of Cef on the mRNA product of either gene (Fig. 7). This indicates that the expression of XCT and GLT-1 is coregulated by ceftriaxone via a translational or trafficking mechanism. Previous reports found ceftriaxone-induced upregulation of GLT-1 (Rothstein et al., 2005) and XCT (Lewerenz et al., 2009) in cell cultures that were continuously treated with Cef, while here we assessed mRNA levels $24 \mathrm{~h}$ following the last Cef injection. Thus, it is also possible that a brief Cef-induced increase in mRNA leads to a stable increase in protein product. Support for this hypothesis comes from a report that GLT-1 mRNA was not upregulated in the dorsal striatum of ischemic rats administered Cef and killed several days after the last Cef injection; however, protein expression was upregulated at this time (Krzyzanowska et al., 2016). Further support for the idea that cocaine/Cef administration alters $\mathrm{xCT}$ trafficking is the presence of relatively modest changes in $\mathrm{xCT}$ expression (Figs. $3 D, 7 H$ ) in the total protein fraction, where we have previously reported robust changes in a membraneenriched fraction (Knackstedt et al., 2010a).

An alternative mechanism of coregulation of xCT and GLT-1 could be that changes in intracellular or extracellular levels of glutamate after cocaine/Cef administration could alter the expression or function of other transporters. Decreased basal levels of extrasynaptic glutamate in cocaine-naive rats did not result in changes in GLT-1 expression (Figs. 4, 6). It is possible that a history of exposure to cocaine and/or Cef is necessary to make the NAc sensitive to this coregulation, perhaps by facilitating the physical association of the transporters. To explore this possibility, we immunoprecipitated GLT-1 in both cocaine and saline self-administering rats treated with Cef or Veh and found no evidence that $\mathrm{xCT}$ and GLT-1 are in physical contact in any condition (Fig. 8).

In conclusion, we have identified both xCT and GLT-1 upregulation as being essential for the ability of Cef to attenuate cue-primed reinstatement of cocaine seeking. We found evidence for coregulation of the expression of these transporters in the presence of both Cef and cocaine, possibly via trafficking or translational mechanisms. While we did not identify a mechanism underlying this coregulation, our findings support previous work that found evidence for functional coregulation, and future work will examine the molecular mechanisms by which Cef exerts regulation of $\mathrm{xCT}$ and GLT-1 expression. Furthermore, we found that decreasing $\mathrm{xCT}$ expression decreases basal glutamate levels in the NAc and leads to compensatory increases in surface GluA1 and GluA2 expression, a result that extends and confirms previous work performed in cell cultures. While these data clearly show a functional relationship between glutamate homeostasis and ionotropic glutamate receptor trafficking, increased surface GluA1 and decreased GLT-1 expression after cocaine administration cannot be solely attributed to decreased basal glutamate levels in the NAc. 


\section{References}

Alhaddad H, Das SC, Sari Y (2014) Effects of ceftriaxone on ethanol intake: a possible role for $\mathrm{xCT}$ and GLT-1 isoforms modulation of glutamate levels in P rats. Psychopharmacology (Berl) 231:4049-4057. CrossRef Medline

Baker DA, Xi ZX, Shen H, Swanson CJ, Kalivas PW (2002) The origin and neuronal function of in vivo nonsynaptic glutamate. J Neurosci 22:91349141. Medline

Baker DA, McFarland K, Lake RW, Shen H, Tang XC, Toda S, Kalivas PW (2003) Neuroadaptations in cystine-glutamate exchange underlie cocaine relapse. Nat Neurosci 6:743-749. CrossRef Medline

Bannai S (1986) Exchange of cystine and glutamate across plasma membrane of human fibroblasts. J Biol Chem 261:2256-2263. Medline

Conrad KL, Tseng KY, Uejima JL, Reimers JM, Heng LJ, Shaham Y, Marinelli M, Wolf ME (2008) Formation of accumbens GluR2-lacking AMPA receptors mediates incubation of cocaine craving. Nature 454:118-121. CrossRef Medline

Cornish JL, Kalivas PW (2000) Glutamate transmission in the nucleus accumbens mediates relapse in cocaine addiction. J Neurosci 20:RC89. Medline

Danbolt NC, Furness DN, Zhou Y (2016) Neuronal vs glial glutamate uptake: resolving the conundrum. Neurochem Int 98:29-45. CrossRef Medline

Epstein DH, Preston KL, Stewart J, Shaham Y (2006) Toward a model of drug relapse: an assessment of the validity of the reinstatement procedure. Psychopharmacology (Berl) 189:1-16. CrossRef Medline

Famous KR, Kumaresan V, Sadri-Vakili G, Schmidt HD, Mierke DF, Cha JH, Pierce RC (2008) Phosphorylation-dependent trafficking of GluR2containing AMPA receptors in the nucleus accumbens plays a critical role in the reinstatement of cocaine seeking. J Neurosci 28:11061-11070. CrossRef Medline

Fischer KD, Houston AC, Rebec GV (2013) Role of the major glutamate transporter GLT1 in nucleus accumbens core versus shell in cue-induced cocaine-seeking behavior. J Neurosci 33:9319-9327. CrossRef Medline

Genda EN, Jackson JG, Sheldon AL, Locke SF, Greco TM, O'Donnell JC, Spruce LA, Xiao R, Guo W, Putt M, Seeholzer S, Ischiropoulos H, Robinson MB (2011) Cocompartmentalization of the astroglial glutamate transporter, GLT-1, with glycolytic enzymes and mitochondria. J Neurosci 31:18275-18288. CrossRef Medline

Ghasemzadeh MB, Vasudevan P, Mueller CR, Seubert C, Mantsch JR (2009) Region-specific alterations in glutamate receptor expression and subcellular distribution following extinction of cocaine self-administration. Brain Res 1267:89-102. CrossRef Medline

Haugeto O, Ullensvang K, Levy LM, Chaudhry FA, Honoré T, Nielsen M, Lehre KP, Danbolt NC (1996) Brain glutamate transporter proteins form homomultimers. J Biol Chem 271:27715-27722. CrossRef Medline

Knackstedt LA, LaRowe S, Mardikian P, Malcolm R, Upadhyaya H, Hedden S, Markou A, Kalivas PW (2009) The role of cystine-glutamate exchange in nicotine dependence in rats and humans. Biol Psychiatry 65:841-845. CrossRef Medline

Knackstedt LA, Melendez RI, Kalivas PW (2010a) Ceftriaxone restores glutamate homeostasis and prevents relapse to cocaine seeking. Biol Psychiatry 67:81-84. CrossRef Medline

Knackstedt LA, Moussawi K, Lalumiere R, Schwendt M, Klugmann M, Kalivas PW (2010b) Extinction training after cocaine self-administration induces glutamatergic plasticity to inhibit cocaine seeking. J Neurosci 30:7984-7992. CrossRef Medline

Krzyzanowska W, Pomierny B, Budziszewska B, Filip M, Pera J (2016) $\mathrm{N}$-Acetylcysteine and ceftriaxone as preconditioning strategies in focal brain ischemia: influence on glutamate transporters expression. Neurotox Res 29:539-550. CrossRef Medline

LaCrosse AL, Hill K, Knackstedt LA (2016) Ceftriaxone attenuates cocaine relapse after abstinence through modulation of nucleus accumbens AMPA subunit expression. Eur Neuropsychopharmacol 26:186-194. CrossRef Medline

Lewerenz J, Albrecht P, Tien ML, Henke N, Karumbayaram S, Kornblum HI, Wiedau-Pazos M, Schubert D, Maher P, Methner A (2009) Induction of $\mathrm{Nrf} 2$ and $\mathrm{xCT}$ are involved in the action of the neuroprotective antibiotic ceftriaxone in vitro. J Neurochem 111:332-343. CrossRef Medline

Liu SJ, Zukin RS (2007) Ca2+-permeable AMPA receptors in synaptic plasticity and neuronal death. Trends Neurosci 30:126-134. CrossRef Medline

Loweth JA, Scheyer AF, Milovanovic M, LaCrosse AL, Flores-Barrera E, Wer- ner CT, Li X, Ford KA, Le T, Olive MF, Szumlinski KK, Tseng KY, Wolf ME (2014) Synaptic depression via mGluR1 positive allosteric modulation suppresses cue-induced cocaine craving. Nat Neurosci 17:73-80. CrossRef Medline

Lu L, Grimm JW, Shaham Y, Hope BT (2003) Molecular neuroadaptations in the accumbens and ventral tegmental area during the first 90 days of forced abstinence from cocaine self-administration in rats. J Neurochem 85:1604-1613. CrossRef Medline

McCutcheon JE, Loweth JA, Ford KA, Marinelli M, Wolf ME, Tseng KY (2011) Group I mGluR activation reverses cocaine-induced accumulation of calcium-permeable AMPA receptors in nucleus accumbens synapses via a protein kinase C-dependent mechanism. J Neurosci 31:14536-14541. CrossRef Medline

McFarland K, Lapish CC, Kalivas PW (2003) Prefrontal glutamate release into the core of the nucleus accumbens mediates cocaine-induced reinstatement of drug-seeking behavior. J Neurosci 23:3531-3537. Medline

Moussawi K, Pacchioni A, Moran M, Olive MF, Gass JT, Lavin A, Kalivas PW (2009) N-Acetylcysteine reverses cocaine-induced metaplasticity. Nat Neurosci 12:182-189. CrossRef Medline

Moussawi K, Zhou W, Shen H, Reichel CM, See RE, Carr DB, Kalivas PW (2011) Reversing cocaine-induced synaptic potentiation provides enduring protection from relapse. Proc Natl Acad Sci U S A 108:385-390. CrossRef Medline

Mulholland PJ, Chandler LJ, Kalivas PW (2016) Signals from the fourth dimension regulate drug relapse. Trends Neurosci 39:472-485. CrossRef Medline

Murphy TH, Miyamoto M, Sastre A, Schnaar RL, Coyle JT (1989) Glutamate toxicity in a neuronal cell line involves inhibition of cystine transport leading to oxidative stress. Neuron 2:1547-1558. CrossRef Medline

O'Brien CP (2003) Research advances in the understanding and treatment of addiction. Am J Addict 12 [Suppl 2]:S36-S47. CrossRef Medline

O’Brien RJ, Kamboj S, Ehlers MD, Rosen KR, Fischbach GD, Huganir RL (1998) Activity-dependent modulation of synaptic AMPA receptor accumulation. Neuron 21:1067-1078. CrossRef Medline

O’Donovan SM, Hasselfeld K, Bauer D, Simmons M, Roussos P, Haroutunian V, Meador-Woodruff JH, McCullumsmith RE (2015) Glutamate transporter splice variant expression in an enriched pyramidal cell population in schizophrenia. Transl Psychiatry 5:e579. CrossRef Medline

Paxinos G, Watson C (2005) The rat brain in stereotaxic coordinates, Ed 5. Boston: Elsevier Academic.

Paxinos G, Watson C (2007) The rat brain in stereotaxic coordinates, Ed 6. New York: Elsevier Academic.

Peters J, Kalivas PW (2006) The group II metabotropic glutamate receptor agonist, LY379268, inhibits both cocaine- and food-seeking behavior in rats. Psychopharmacology (Berl) 186:143-149. CrossRef Medline

Ping A, Xi J, Prasad BM, Wang MH, Kruzich PJ (2008) Contributions of nucleus accumbens core and shell GluR1 containing AMPA receptors in AMPA- and cocaine-primed reinstatement of cocaine-seeking behavior. Brain Res 1215:173-182. CrossRef Medline

Purgianto A, Scheyer AF, Loweth JA, Ford KA, Tseng KY, Wolf ME (2013) Different adaptations in AMPA receptor transmission in the nucleus accumbens after short vs long access cocaine self-administration regimens. Neuropsychopharmacology 38:1789-1797. CrossRef Medline

Rao PS, Sari Y (2014) Effects of ceftriaxone on chronic ethanol consumption: a potential role for $\mathrm{xCT}$ and GLT1 modulation of glutamate levels in male P rats. J Mol Neurosci 54:71-77. CrossRef Medline

Rao PSS, Goodwani S, Bell RL, Wei Y, Boddu SHS, Sari Y (2015) Effects of ampicillin, cefazolin and cefoperazone treatments on GLT-1 expressions in the mesocorticolimbic system and ethanol intake in alcohol-preferring rats. Neuroscience 295:164-174. CrossRef Medline

Reissner KJ, Sartor GC, Vazey EM, Dunn TE, Aston-Jones G, Kalivas PW (2012) Use of vivo-morpholinos for control of protein expression in the adult rat brain. J Neurosci Methods 203:354-360. CrossRef Medline

Reissner KJ, Gipson CD, Tran PK, Knackstedt LA, Scofield MD, Kalivas PW (2015) Glutamate transporter GLT-1 mediates N-acetylcysteine inhibition of cocaine reinstatement. Addict Biol 20:316-323. CrossRef Medline

Rimaniol AC, Mialocq P, Clayette P, Dormont D, Gras G (2001) Role of glutamate transporters in the regulation of glutathione levels in human macrophages. Am J Physiol Cell Physiol 281:C1964-C1970. Medline

Rimmele TS, Rosenberg PA (2016) GLT-1: the elusive presynaptic glutamate transporter. Neurochem Int 98:19-28. CrossRef Medline

Rothstein JD, Patel S, Regan MR, Haenggeli C, Huang YH, Bergles DE, Jin L, 
Dykes Hoberg M, Vidensky S, Chung DS, Toan SV, Bruijn LI, Su ZZ, Gupta P, Fisher PB (2005) Beta-lactam antibiotics offer neuroprotection by increasing glutamate transporter expression. Nature 433:73-77. CrossRef Medline

Sari Y, Smith KD, Ali PK, Rebec GV (2009) Upregulation of GLT1 attenuates cue-induced reinstatement of cocaine-seeking behavior in rats. J Neurosci 29:9239-9243. CrossRef Medline

Schmidt HD, Kimmey BA, Arreola AC, Pierce RC (2015) Group I metabotropic glutamate receptor-mediated activation of PKC gamma in the nucleus accumbens core promotes the reinstatement of cocaine seeking. Addict Biol 20:285-296. CrossRef Medline

Shan D, Mount D, Moore S, Haroutunian V, Meador-Woodruff JH, McCullumsmith RE (2014) Abnormal partitioning of hexokinase 1 suggests disruption of a glutamate transport protein complex in schizophrenia. Schizophr Res 154:1-13. CrossRef Medline

Smith AC, Scofield MD, Heinsbroek JA, Gipson CD, Neuhofer D, RobertsWolfe DJ, Spencer S, Garcia-Keller C, Stankeviciute NM, Smith RJ, Allen NP, Lorang MR, Griffin WC 3rd, Boger HA, Kalivas PW (2017) Accumbens nNOS interneurons regulate cocaine relapse. J Neurosci 37:742-756. CrossRef Medline

Sondheimer I, Knackstedt LA (2011) Ceftriaxone prevents the induction of cocaine sensitization and produces enduring attenuation of cue- and cocaine-primed reinstatement of cocaine-seeking. Behav Brain Res 225: 252-258. CrossRef Medline
Sun X, Wolf ME (2009) Nucleus accumbens neurons exhibit synaptic scaling that is occluded by repeated dopamine pre-exposure. Eur J Neurosci 30:539-550. CrossRef Medline

Tanaka K, Watase K, Manabe T, Yamada K, Watanabe M, Takahashi K, Iwama H, Nishikawa T, Ichihara N, Kikuchi T, Okuyama S, Kawashima N, Hori S, Takimoto M, Wada K (1997) Epilepsy and exacerbation of brain injury in mice lacking the glutamate transporter GLT-1. Science 276:1699-1702. CrossRef Medline

Trantham-Davidson H, LaLumiere RT, Reissner KJ, Kalivas PW, Knackstedt LA (2012) Ceftriaxone normalizes nucleus accumbens synaptic transmission, glutamate transport, and export following cocaine selfadministration and extinction training. J Neurosci 32:12406-12410. CrossRef Medline

Wang X, Moussawi K, Knackstedt L, Shen H, Kalivas PW (2013) Role of mGluR5 neurotransmission in reinstated cocaine-seeking. Addict Biol 18:40-49. CrossRef Medline

White SL, Ortinski PI, Friedman SH, Zhang L, Neve RL, Kalb RG, Schmidt HD, Pierce RC (2016) A critical role for the GluAl accessory protein, SAP97, in cocaine seeking. Neuropsychopharmacology 41:736-750. CrossRef Medline

Xie X, Lasseter HC, Ramirez DR, Ponds KL, Wells AM, Fuchs RA (2012) Subregion-specific role of glutamate receptors in the nucleus accumbens on drug context-induced reinstatement of cocaine-seeking behavior in rats. Addict Biol 17:287-299. CrossRef Medline 